\title{
Endocrown restorations: Influence of dental remnant and restorative material on stress distribution ${ }^{\text {is }}$
}

\author{
João Paulo Mendes Tribst ${ }^{a}$, Amanda Maria de Oliveira Dal Piva ${ }^{a, *}$, \\ Camila Ferreira Leite Madruga ${ }^{a}$, Marcia Carneiro Valera ${ }^{b}$, \\ Alexandre Luiz Souto Borges ${ }^{a}$, Eduardo Bresciani ${ }^{b}$, \\ Renata Marques de Melo ${ }^{a}$
}

a Department of Dental Materials and Prosthodontics, São Paulo State University (Unesp), Institute of Science and Technology, Av. Eng. Francisco José Longo, $n^{\circ}$ 777, Jardim São Dimas, 12245-000 São José dos Campos, SP, Brazil

b Department of Restorative Dentistry, São Paulo State University (Unesp), Institute of Science and Technology, Av. Eng. Francisco José Longo, $n^{\circ}$ 777, Jardim São Dimas, 12245-000 São José dos Campos, SP, Brazil

\section{A R T I C L E I N F O}

\section{Article history:}

Received 13 December 2017

Received in revised form 8 May 2018

Accepted 7 June 2018

Keywords:

Ceramics

Monoblock restoration

Endodontically treated teeth

Finite element analysis

Dental restoration failure

\begin{abstract}
A B S T R A C T
Objective. The goal of this study was to evaluate the stress distribution in a tooth/restoration system according to the factors "amount of dental remnant" (3 levels) and "restorative material" (2 levels).

Methods. Three endodontically treated maxillary molars were modeled with CAD software for conducting non-linear finite element analysis (FEA), each with a determined amount of dental remnant of $1.5,3$, or $4.5 \mathrm{~mm}$. Models were duplicated, and half received restorations in lithium disilicate (IPS e.max CAD), while the other half received leucite ceramic restorations (IPS Empress CAD), both from Ivoclar Vivadent (Schaan, Liechtenstein). The solids were imported to analysis software (ANSYS 17.2, ANSYS Inc., Houston, TX, USA) in STEP format. All contacts involving the resin cement were considered no-separation, whereas between teeth and fixation cylinder, the contact was considered perfectly bonded. The mechanical properties of each structure were reported, and the materials were considered isotropic, linearly elastic, and homogeneous. An axial load (300 N) was applied at the occlusal surface (triploidism area). Results were determined by colorimetric graphs of maximum principal stress (MPS) on tooth remnant, cement line, and restoration.

Results. MPS revealed that both factors influenced the stress distribution for all structures; the higher the material's elastic modulus, the higher the stress concentration on the restoration and the lower the stress concentration on the cement line. Moreover, the greater the dental crown remnant, the higher the stress concentration on the restoration. Thus, the remaining dental tissue should always be preserved.
\end{abstract}

\footnotetext{
* Corresponding author.

E-mail addresses: joao.tribst@ict.unesp.br (J.P.M. Tribst), amanda.piva@ict.unesp.br (A.M.d.O. Dal Piva), camila.domingues@ict.unesp.br (C.F.L. Madruga), marcia@ict.unesp.br (M.C. Valera), aleborges@ict.unesp.br (A.L.S. Borges), eduardob@ict.unesp.br (E. Bresciani), renata.marinho@ict.unesp.br (R.M. de Melo).

This research was recently awarded with an honorable mention as Oral presentation on the 34th Brazilian Society of Dental Research - SBPqO, the Brazilian division of the International Association for Dental Research - IADR, Campinas, BRA.

https://doi.org/10.1016/j.dental.2018.06.012

0109-5641/@ 2018 The Academy of Dental Materials. Published by Elsevier Inc. All rights reserved.
} 
Significance. In situations in which few dental remnants are available, the thicker the restoration, the higher the concentration of stresses in its structure, protecting the adhesive interface from potential adhesive failures. Results are more promising when the endocrown is fabricated with lithium disilicate ceramic.

(C) 2018 The Academy of Dental Materials. Published by Elsevier Inc. All rights reserved.

\section{Introduction}

Due to the complexity of rehabilitating endodontically treated teeth, several systems have emerged and have been developed in an attempt to recover function and aesthetics. In cases of great tooth structure loss, post-retained restorations are widely used [1]. Among those, prefabricated fiberglass posts have received considerable attention in the scientific literature [2-4], industry, and clinicians' routines due to their advantages such as: aesthetics, homogeneous stress distribution due to their elastic modulus similar to that of dentin [5], ease of handling, and proven clinical success. Despite all the benefits, fiber posts serve only to create adequate retention for the resin composite core to support a full crown. This indication is similar to metal posts, in which previous preparation of the root canal is required, involving removal of part of the endodontic obturation and widening of the canal, thereby possibly decreasing the fracture resistance of dental remnants [6]. Conversely, when a minimum amount of dental remnant exists, it allows for an adhesive interface between enamel and cement, enabling an endocrown restoration to be used [7].

An endocrown consists of a monolithic restoration whose anchorage occurs in the pulp chamber [8]. Its main advantage is related to the fact that it does not require root dentin removal for the retainer installation, in addition to preventing the risk of recontamination during disobturation. Conventional total crown preparations lead to greater tooth wear, longer clinical time, and laboratory costs compared with dental preparations receiving endocrown restorations [7]. Endocrown restorations can be milled by CAD/CAM technology (Computer-aided Design/Computer-aided Manufacture), which minimizes clinical adjustment procedures and the incorporation of defects during preparation, as well as allowing the treatment to be performed in a single session [7]. Recent studies have confirmed the use of such a technique for manufacturing restorations in resin composite, nanoceramic resin, lithium disilicate glass ceramic [8], zirconia-reinforced lithium silicate $[7,9]$, hybrid ceramic, and feldspathic ceramic $[8,9]$. The great number of different materials available that can be used with such technology allows clinicians to choose the material that is most suitable for them. In addition, those materials might also be used in smaller restorations such as ceramic inlays and onlays, in which preparation is minimally invasive. Thus, an endodontically treated tooth requiring indirect restoration due to great occlusal destruction is a candidate to receive the aforementioned materials. Conversely, the pulp chamber is not always used for extra retention in ceramic restorations, and an endocrown restoration with limited occlusal thickness should be considered for tooth rehabilitation, taking into account all the benefits of such a minimally invasive restorative modality.
For evaluation of the stress distribution generated by masticatory loads in endodontically treated teeth, finite element analysis (FEA) has been used [4] due to specimen standardization, low cost, and because it is a numerical method that offers a means to find an approximate solution. Such analysis is able to detect stress concentration regions that might undergo failure [10]. Usually, failure origin consists of points of greater stress concentration previously evidenced by FEA. Thus, the objective of the present study was to evaluate the influence of dental remnants (at 3 levels - endocrowns with different heights) and the type of restorative material (at 2 levels) on the biomechanical behavior of endocrown restorations. The hypotheses were that (1) the amount of dental remnant and (2) the type of restorative material would not interfere in the stress distribution of the rehabilitative procedure.

\section{Materials and methods}

\subsection{Generation of the geometric model}

A 3D model of a sound tooth was scanned (InEos, Sirona Dental Systems $\mathrm{GmbH}$, Bensheim, Germany) to generate a stereolithography file. The file was exported to the CAD software Rhinoceros (Rhinoceros version 5.0 SR8, McNeel North America, Seattle, WA, USA) as a polygon mesh composed of 19,100 faces. For the creation of the geometric model with the tooth macro-structure, a volumetric model is needed. Thus, the command "reduce mesh", available as a plugin in the CAD software, was used, with $50 \%$ relevance to smooth the structure with all normal faces oriented in the same direction. The next step was the use of "RhinoResurf", a reverse engineering tool that gives the CAD software the ability to reconstruct NURBS surfaces from a mesh or point cloud with specified precision. A 3D volumetric model of a molar was then created based on the surface created by the curve network generated automatically. Three models were replicated, and the command "cut plane" was used to cut the crown of each model at different remnant levels $(1.5 \mathrm{~mm}, 3 \mathrm{~mm}$, or $4.5 \mathrm{~mm})$. Each sectioned model had a pulp chamber of 5-mm depth and a $16^{\circ}$ wall inclination angle. The endocrown was then formed by the pulp chamber extension, and the portion corresponding to the occlusal was cut by a Boolean union. The cement layer was modeled with $70-\mu \mathrm{m}$ thickness [11] between the internal surfaces of the restoration and bonding surfaces of the teeth.

\subsection{Finite element analysis (FEA)}

Three different restoration geometries (Fig. 1) were obtained to evaluate different amounts of dental remnant (heights). The three models were inserted into a polyurethane cylinder 
Table 1 - Group distribution according to the amount of dental remnant $(\mathrm{mm})$ and restorative material type, and descriptive statistics according to the maximum principal stress peaks (MPa) obtained in the restoration, cement line, and tooth.

\begin{tabular}{|c|c|c|c|c|c|c|c|c|c|c|c|c|c|c|}
\hline \multirow[t]{2}{*}{ Group } & \multirow[t]{2}{*}{ Dental remnant } & \multirow[t]{2}{*}{ Restorative material } & \multicolumn{4}{|c|}{ Endocrown } & \multicolumn{4}{|c|}{ Cement layer } & \multicolumn{4}{|c|}{ Tooth } \\
\hline & & & Mean & SD & Min. & Max. & Mean & SD & Min. & Max. & Mean & $\mathrm{SD}$ & Min. & Max. \\
\hline D1.5 & 1.5 & Lithium-disilicate & 19.6 & 2.1 & 17.3 & 23.5 & 41.9 & 1.7 & 39.8 & 44.9 & 14.8 & 0.9 & 13.6 & 16.6 \\
\hline D3 & 3 & glass-ceramic & 17.8 & 2.6 & 14.8 & 22.3 & 41.0 & 2.1 & 38.3 & 44.6 & 15.4 & 1.5 & 13.1 & 17.4 \\
\hline D4.5 & 4.5 & & 18.0 & 2.8 & 15.0 & 22.7 & 39.6 & 3.0 & 32.9 & 44.6 & 14.5 & 1.9 & 12.4 & 17.3 \\
\hline L1.5 & 1.5 & Leucite-reinforced & 17.4 & 2.0 & 15.2 & 20.7 & 41.7 & 2.1 & 39.1 & 44.5 & 14.2 & 0.9 & 12.7 & 16.1 \\
\hline L3 & 3 & glass-ceramic & 16.5 & 2.3 & 13.4 & 19.5 & 40.7 & 2.1 & 37.7 & 44.5 & 14.1 & 1.3 & 12.2 & 15.8 \\
\hline L4.5 & 4.5 & & 15.8 & 2.0 & 13.5 & 18.8 & 38.2 & 3.5 & 30.0 & 43.4 & 13.8 & 1.3 & 12.0 & 15.9 \\
\hline
\end{tabular}

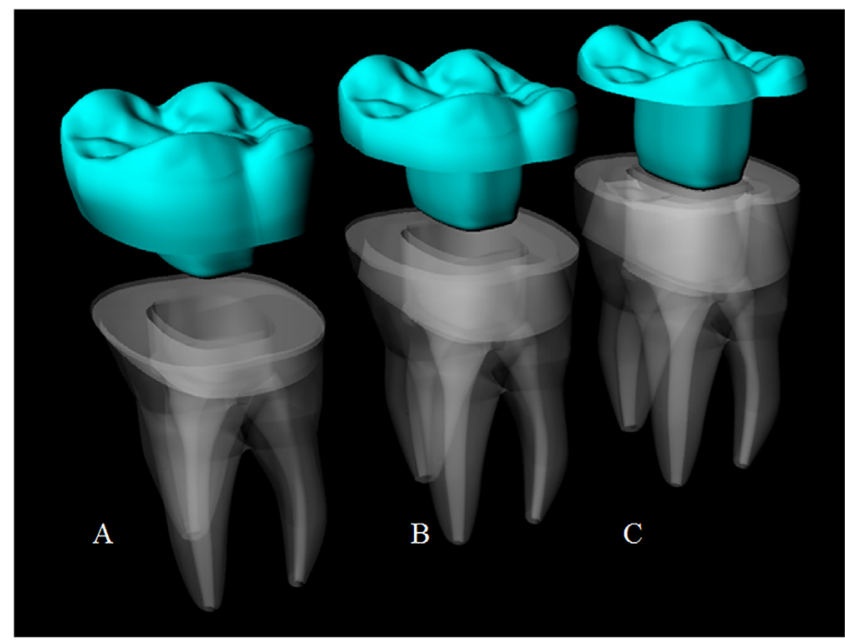

Fig. 1 - Schematic illustration of the modeling. (A) Remaining amount of $1.5 \mathrm{~mm}$ restored with $4.5 \mathrm{~mm}$ endocrown. (B) Remaining amount of $3 \mathrm{~mm}$ restored with a 3-mm endocrown. (C) Remaining amount of $4.5 \mathrm{~mm}$ restored with a 1.5-mm endocrown.

and duplicated so that half received lithium disilicate glassceramic restorations [IPS e.max CAD/Ivoclar Vivadent, Schaan, Liechtenstein; elastic modulus $(E)=95 \mathrm{GPa}$ and Poisson ratio $(v)=0.33$ ] [12], and the other half received leucite-reinforced glass-ceramic restorations (IPS Empress CAD/Ivoclar Vivadent; $\mathrm{E}=64.9 \mathrm{GPa}$ and $v=0.2$ ) [13], totaling 6 groups (Table 1 ). The amount of dental remnant (Enamel, $E=84.1 \mathrm{GPa}$ and $v=0.33$; Dentin, $\mathrm{E}=18.6 \mathrm{GPa}$ and $v=0.32)[14,15]$ and endocrown height resulted in a $6-\mathrm{mm}$ system for all groups. Polyurethane mimics bone tissue and is widely used in in vitro and in silico (mathematical) studies due to its elastic modulus ( $\mathrm{E}=4 \mathrm{MPa})$, having been validated as a substitute for human bone tissue. The incorporated resin cement had $\mathrm{E}=6 \mathrm{GPa}$ and $v=0.30$ (linear shrinkage $=2.7 \%)[11]$

The models were imported through STEP format for the analysis software (ANSYS 17.2, ANSYS Inc., Houston, TX, USA), in which they were divided into mesh composed of nodes $(196,716)$ and tetrahedral elements (94,896) (Fig. 2). The aspect ratio of the mesh elements presented an average of $1.8 \pm 0.5$. Mechanical properties of each material/structure used were inserted into the analysis software, and each material was considered isotropic, elastic, and homogeneous. No-separation contacts were considered between restora-
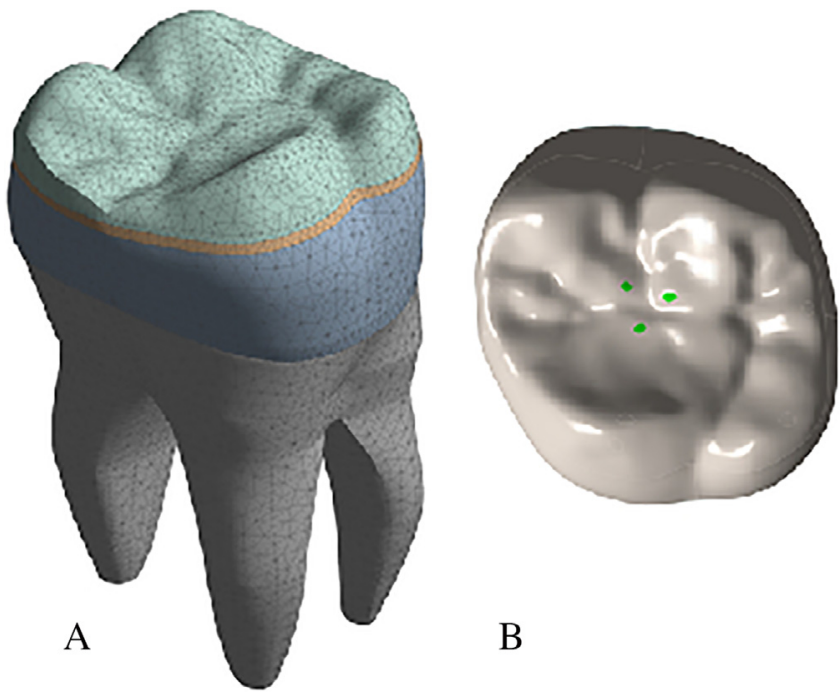

Fig. 2 - (A) Mesh generation. (b) 300-N load application area/points.

tion/resin cement and resin cement/tooth, in which the target and contact surfaces were tied for the remainder of the analysis, although sliding was permitted. Between the tooth and the fixation cylinder, the contact was considered perfectly bonded. In all groups, the model fixation occurred at the base of the polyurethane cylinder with fixed zero nodal displacements [11], and an axial load of $300 \mathrm{~N}$ [16-19] was applied to the occlusal surface based on the tripoidism concept [20-22]. A mesh convergence test $(10 \%)$ was performed to guarantee that it would not interfere with the results [23]. To simulate polymerization shrinkage effects of adhesive layers and bulk fill composite, the thermal expansion approach was used. Assuming a one-degree drop in temperature, the adhesive layer would shrink and generate stress at the tooth-restoration interface [11]. Tensile stress peaks recorded from the paths buccolingually directed and located on the adhesive interface (on the endocrown intaglio surface, cement layer, and on the dental remnant) [24] were statistically analyzed by two-way Analysis of Variance (ANOVA), $\alpha=0.05$.

\section{Results}

Maximum Principal Stress (MPS) results were obtained for the endocrown, cement layer, and dental remnant struc- 


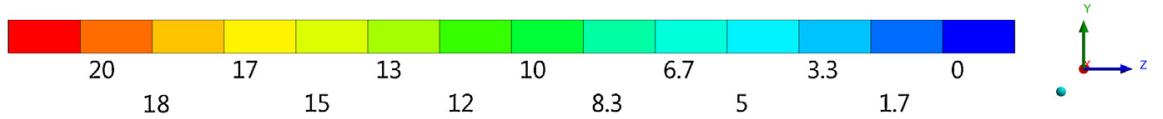

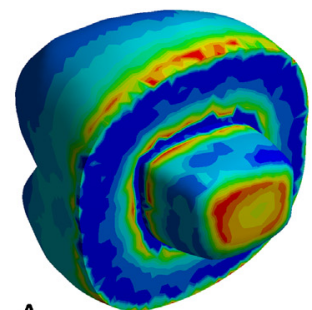

A
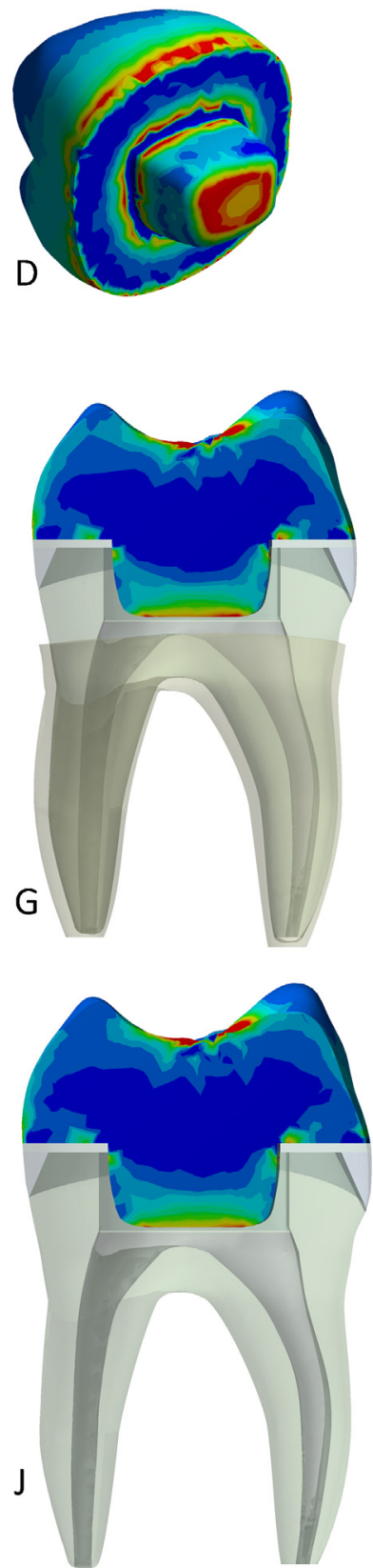

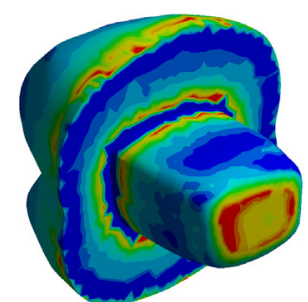

B
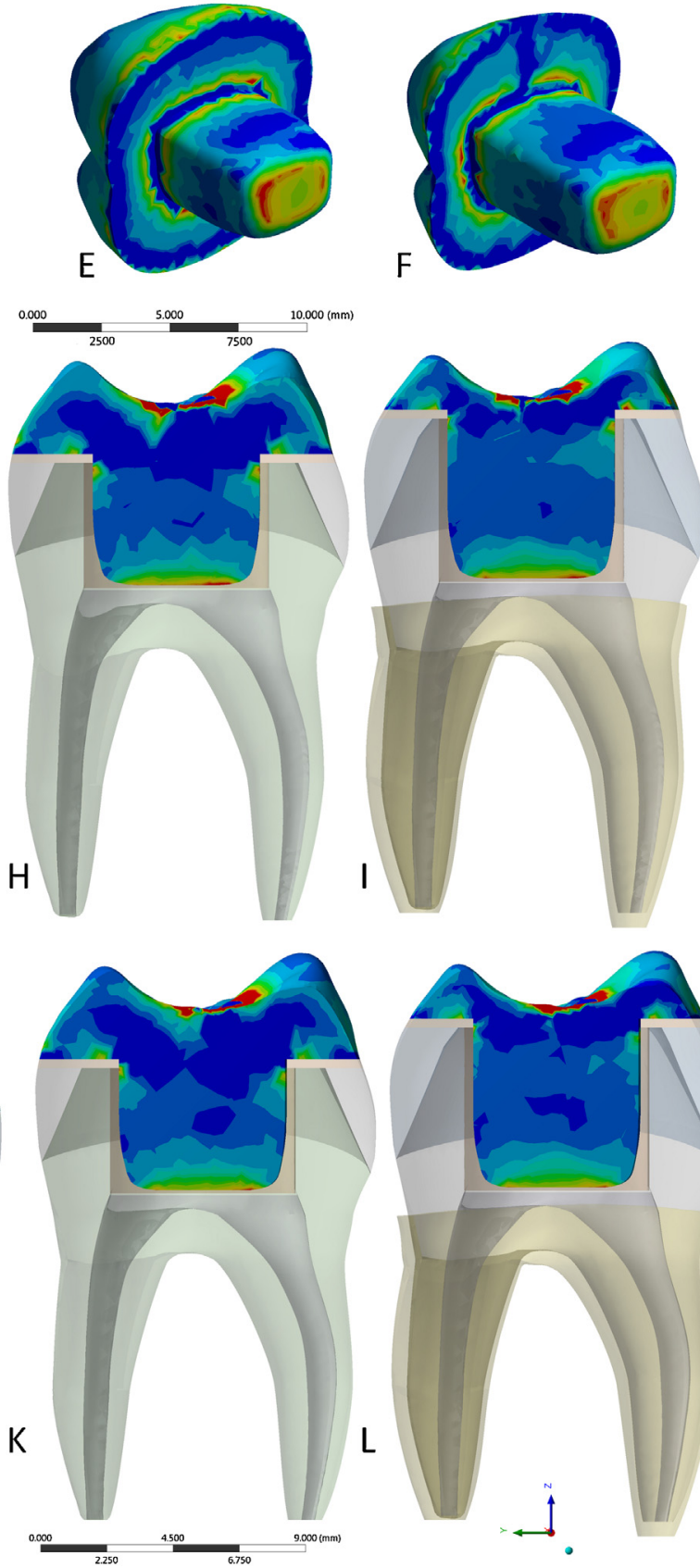

Fig. 3 - MPS in endocrown restorations (lower view, A-F; coronal view, G-L) according to dental remnant amount (1.5, 3, and $4.5 \mathrm{~mm}$, from left to right) and restorative material type (first and third rows, lithium disilicate; second and fourth rows, leucite). 
tures. Data were summarized through colorimetric graphs (Figs. 3-5). For the endocrown restoration and the cement layer (Figs. 3 and 4), less stress concentration was observed for higher remnants, which was even better when the leucite ceramic was used. On the tooth surfaces, less stress concentration was also observed for the higher tooth remnants. Regarding the restorative material, lithium disilicate presented more stress concentration in the restoration and in the teeth.

A summary of the means, standard deviations, and minimum and maximum values of the stress peaks is presented in Table 1. Two-way ANOVA of the mean stress peaks showed that factor material type affected the stress distribution in the endocrown $(p=0.003)$ and in the dental remnant $(p=0.019)$. Lithium disilicate demonstrated higher mean stresses than leucite-based ceramic for both the endocrown and the tooth. For the cement, only the dental remnant influenced the stress distribution $(p=0.002)$. The stress generated on the cement layer was similar between 1.5 and $3 \mathrm{~mm}$ of dental remnant, while the $4.5 \mathrm{~mm}$ of dental remnant resulted in less stress.

\section{Discussion}

The purpose of this study was to evaluate the influence of "dental remnant amount" and "restorative material type" on the biomechanical behavior of endocrown restorations. Through finite element analysis (FEA) methodology, it was possible to show that both factors influenced the biomechanical behavior of restorations. Thus, the hypotheses of this study were rejected. With CAD/CAM technology, it is possible to obtain restorations with less need for adjustments, proper margins, and less incorporation of structural defects [7]. Among machinable materials, lithium-disilicatebased ceramics have aesthetic and mechanical qualities that have been previously substantiated in the literature [8]. Leucite-reinforced glass-ceramic has been evaluated as an alternative to lithium disilicate for endocrown restorations and presented bonding strength to dentin similar to that of lithium disilicate [25], but with lower mechanical strength [26].
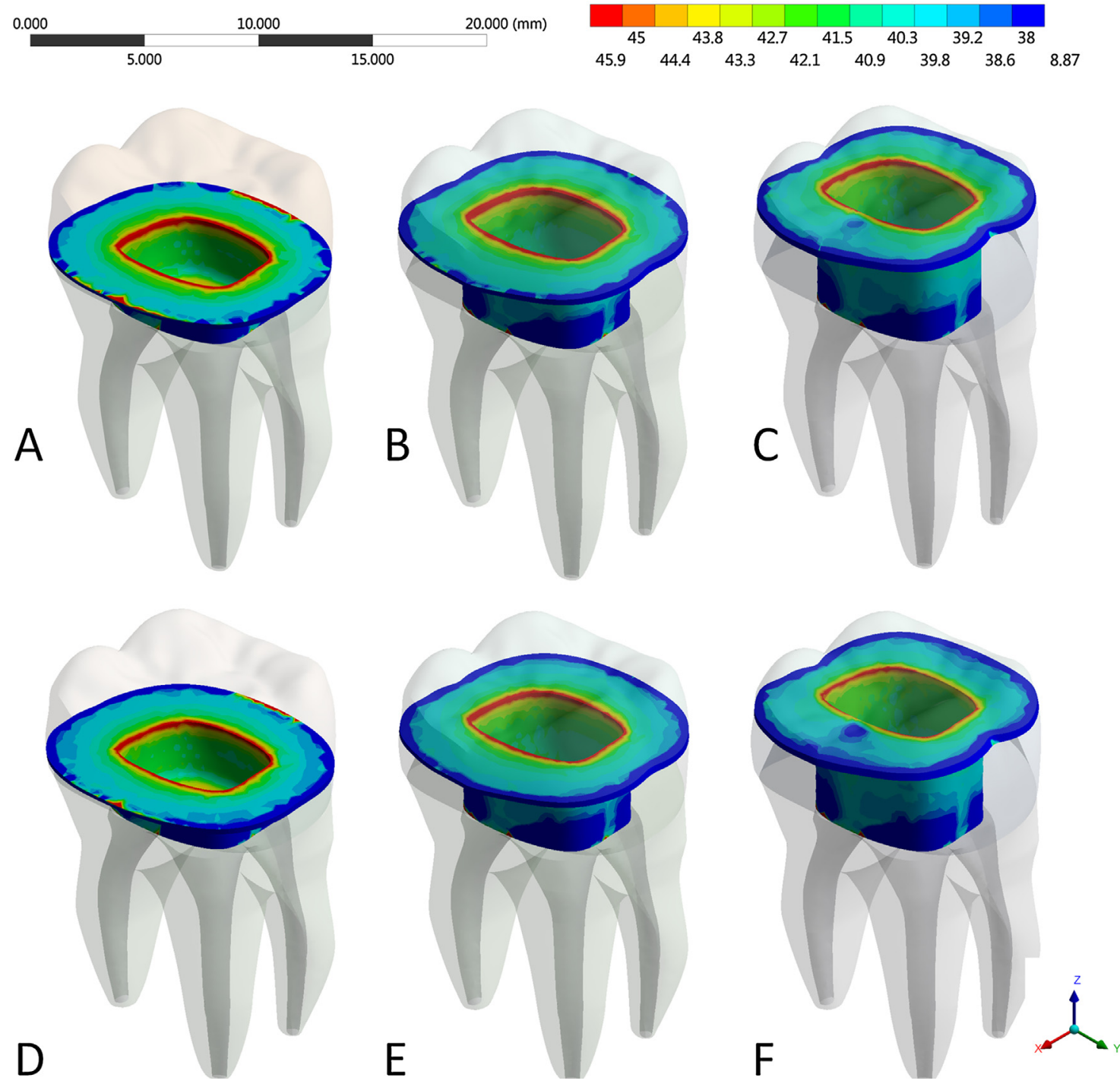

Fig. 4 - MPS in cement line according to dental remnant amount (1.5, 3, and $4.5 \mathrm{~mm}$, from left to right) and restorative material type (first row, lithium disilicate; and second row, leucite). 


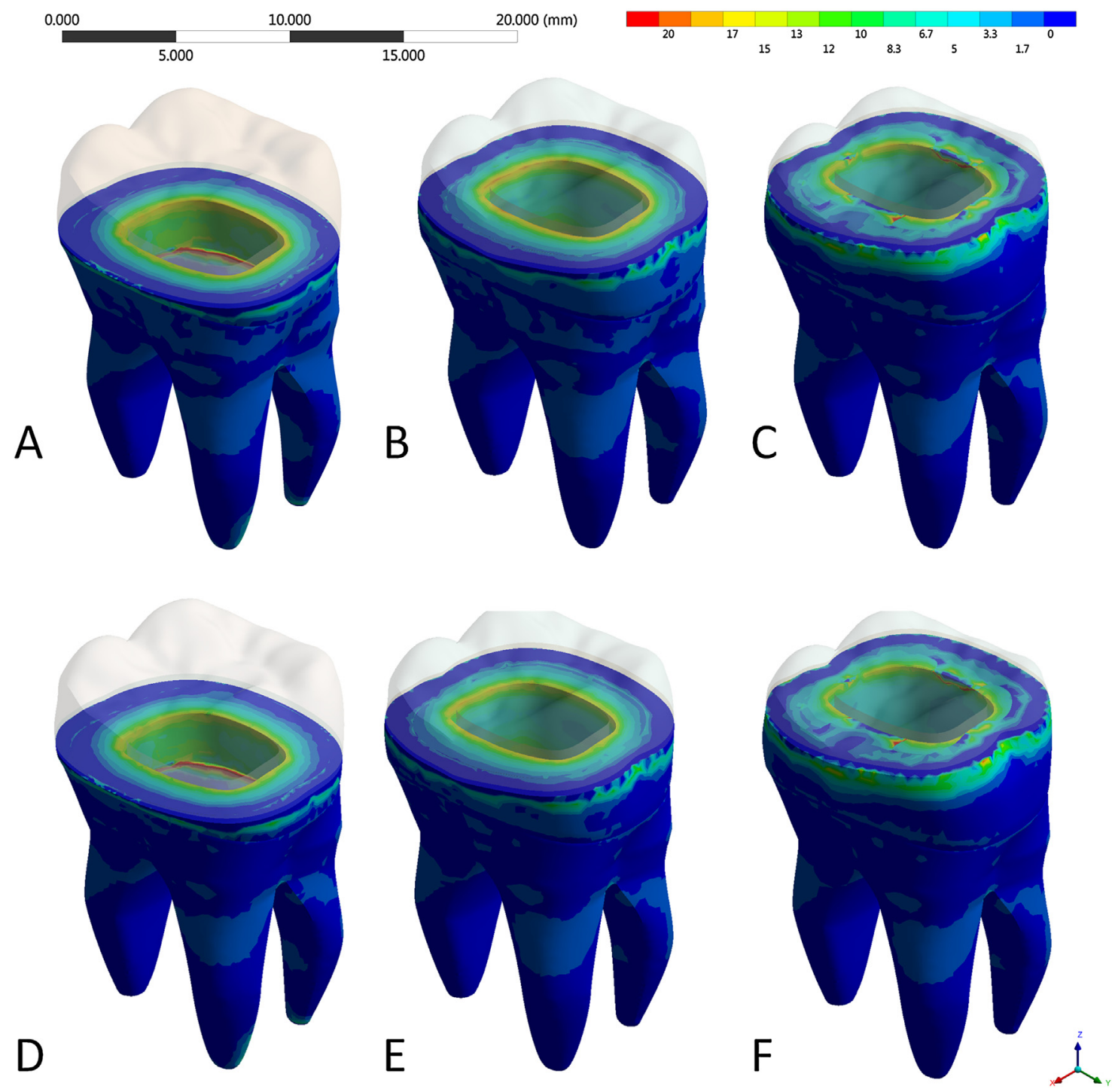

Fig. 5 - MPS in remaining tooth according to dental remnant amount (1.5, 3, and $4.5 \mathrm{~mm}$, from left to right) and restorative material type (first row, lithium disilicate; and second row, leucite).

\subsection{Endocrown}

Through the present mathematical analysis, it was observed that the stress peaks observed in all different restorations were not sufficient $(27 \mathrm{MPa})$ to reach the fracture resistance threshold of both materials. Through color graphs, it is suggested that both factors influenced the stress distribution in endocrown restorations. Lithium disilicate glass-ceramic concentrated more stress than leucite-reinforced glass-ceramic (Table 1). Regarding the dental remnant amount, the thinner the restoration, the lower the stress concentration (Fig. 3A-F). In a longitudinal section, it was observed that the stress concentration was mainly on the crown surface (Fig. 3G-L). However, considering the stress peaks $(n=20)$, two-way ANOVA showed that only material type statistically influenced the stress distribution in the endocrown.

According to the manufacturer, the biaxial flexural strengths for leucite and lithium disilicate are $160 \mathrm{MPa}$ and $360 \mathrm{MPa}$, respectively, allowing for the obtention of restora- tions of increased load-bearing capacity. Longitudinal studies are necessary to verify if stress concentration regions generated in endocrowns would be susceptible to crack propagation during fatigue. Therefore, the results show that lithium disilicate concentrates more stress than leucite in all studied conditions due to its greater elastic modulus [10], impairing stress transmission to the surrounding structure. In spite of the frequent presence of critical regions as observed (Fig. 3), lithium disilicate presents crystalline particles that increase the material fracture toughness against mechanical injury $[8,26]$, leading to superior strength compared with that of leucite ceramics.

Indeed, adhesive failure is the main reason for failure in endocrown restorations [27], and such a characteristic might be complicated in lithium disilicate restorations, since the stress at the adhesive interface is slightly higher, therefore making leucite an interesting alternative.

Zhu et al. [10] evaluated the biomechanics of endocrown restorations in maxillary premolars and found that the 
restoration thickness influenced the stress distribution in the restoration. The authors showed that thicker endocrowns concentrated more stress, leading to lower stress on surrounding structures when compared with that on thinner restorations, which suggests that there would be no future detachment. Herein, it was observed that the colorimetric graphs of the groups were slightly different and that the stress peaks were not statistically significant. It is important to emphasize that the previous authors [10] did not simulate resin cement shrinkage [11], which could have modified the results obtained. Also, incident loads on molars are predominantly axial, and any alteration of tooth anatomy or off-axis loading would alter the generated stress which, in turn, could facilitate adhesion loss or tooth fracture, as previously reported $[28,29]$.

\subsection{Cement line}

The dental remnant factor was significant for the cement line. Thus, the greater the amount of dental remnant, the lower the stress concentration in the cement line (Fig. 4A-F). Both materials presented similar behavior, mainly in the internal portion of the restoration. Conversely, lithium disilicate presented the higher stress peak (44.9 MPa) on the cement line for $1.5 \mathrm{~mm}$ of dental remnant (Table 1). Polymerization shrinkage represents one of the main causes of leakage in dental restorations, as reported in the literature [11]. Since cement polymerization shrinkage is a centrifugal contraction, the restoration margins may be more susceptible to infiltration, facilitating leakage. The gap formed between restoration and tooth may be a region susceptible to biofilm accumulation that enables caries to occur. Through the thermal analogy, it is possible to simulate, in finite element analysis, the polymerization shrinkage of the resinous materials through the coefficient of linear thermal shrinkage value [11]. Herein, the cement layers presented the highest stress values, ranging from 30 to $44.9 \mathrm{MPa}$, compared with the values of stress in the restorations, which reached a maximum of $23.5 \mathrm{MPa}$ (Table 1). The colorimetric stress map (Fig. 4) shows little difference between the groups, but the statistical analysis of the tensile stress peaks showed that the dental remnant influenced the results. Further in vitro and clinical studies are necessary to confirm our theoretical findings.

\subsection{Dental remnant}

Regarding the dental remnant structure, it was observed that lithium disilicate tends to concentrate more stress on the surface of the remaining tooth compared with its leucitereinforced glass-ceramic counterpart (Table 1). Enamel is a dental tissue of high elastic modulus and concentrates stress whenever it is present. Therefore, regardless of the tooth remnant amount, the stress distribution was the same due to the presence of surrounding enamel in all groups. The surface of the surrounding enamel was considerably present (Fig. 5A, D).

It is known that enamel is responsible for greater bond strength in dental structures, and its maintenance directly influences restoration longevity [30-32]. This interpretation is validated, since dentin has a lower elastic modulus and exhibits a less critical pattern of stress for all groups - a fact detected due to dentin's ability to dissipate occlusal loads. The color pattern generated in dentin is similar for all groups (Fig. 5). However, since the long-term adhesive stability in dentin is doubtful [32], it is not possible to assume adequate maintenance of restorations in service, even if the generated stress is relatively subtle.

The second factor evaluated, "restorative material type", influenced the results related to tooth remnant. Groups restored with leucite (Fig. $5 \mathrm{~A}-\mathrm{C}$ ) presented less stress, thus suggesting better biomechanical behavior and less probability of fracture in dental structures compared with lithium disilicate ceramic (Fig. 5D-F).

\section{Conclusions}

Within the limits of this study, the following conclusions may be drawn:

- Dental tissue remnant must always be preserved.

- In situations where limited tooth remnant is available, the thinner the restoration, the higher the stress concentration in its structure, thus protecting the adhesive interface from possible adhesive failures.

- Leucite presented a better stress distribution, thus being a promising alternative to lithium disilicate for the manufacture of endocrown restorations.

\section{REFERENCES}

[1] Schwendicke F, Stolpe M. Cost-effectiveness of different post-retained restorations. J Endod 2017;43:709-14.

[2] Gomes GM, Gomes OMM, Reis A, Gomes JC, Loguercio AD, Calixto AL. Regional bond strengths to root canal dentin of fiber posts luted with three cementation systems. Braz Dent J 2011;22:460-7.

[3] Dal Piva AMO, Campos F, Alves MLL, Sousa RS, Lima JMC, Souza ROA. Influence of alveolar bone level on the pull-out bond strength of fiber-reinforced composite posts to root dentin. Gen Dent 2016;64:e5-8.

[4] Dal Piva AM, Tribst JP, Souza RO, Borges AL. Influence of alveolar bone loss and cement layer thickness on the biomechanical behavior of endodontically treated maxillary incisors: a 3-dimensional finite element analysis. J Endod 2017;43:791-5.

[5] Barbizam JV, White SN. Fatigue susceptibility of an endodontic fibre post material. J Int Endod 2014;47:202-9.

[6] Junqueira RB, de Carvalho RF, Marinho CC, Valera MC, Carvalho CAT. Influence of glass fiber post length and remaining dentine thickness on the fracture resistance of root filled teeth. Int Endod J 2017;50:569-77.

[7] da Cunha LF, Gonzaga CC, Pissaia JF, Correr GM. Lithium silicate endocrown fabricated with a CAD-CAM system: a functional and esthetic protocol. J Prosthet Dent 2017;118:131-4.

[8] El-Damanhoury HM, Haj-Ali RN, Platt JA. Fracture resistance and microleakage of endocrowns utilizing three CAD-CAM blocks. Oper Dent 2015;40:201-10.

[9] Aktas G, Yerlikaya H, Akca K. Mechanical failure of endocrowns manufactured with different ceramic materials: an in vitro biomechanical study. J Prosthodont 2016:1-7.

[10] Zhu J, Rong Q, Wang X, Gao X. Influence of remaining tooth structure and restorative material type on stress 
distribution in endodontically treated maxillary premolars: a finite element analysis. J Prosthet Dent 2017;117:646-55.

[11] Ausiello P, Ciaramella S, Fabianelli A, Gloria A, Martorelli M, Lanzotti A, et al. Mechanical behavior of bulk direct composite versus block composite and lithium disilicate indirect class II restorations by CAD-FEM modeling. Dent Mater 2017;33:690-701.

[12] Ma L, Guess PC, Zhang Y. Load-bearing properties of minimal-invasive monolithic lithium disilicate and zirconia occlusal onlays: finite element and theoretical analyses. Dent Mater 2013;29:742-51.

[13] Imanishi A, Nakamura T, Ohyama T, Nakamura T. 3-D finite elemento analysis of all-ceramic posterior crowns. J Oral Rehabil 2003;30:818-22.

[14] Roscoe MG, Noritomi PY, Novais VR, Soares CJ. Influence of alveolar bone loss, post type, and ferrule presence on the biomechanical behavior of endodontically treated maxillary canines: strain measurement and stress distribution. J Prosthet Dent 2013;110:116-26.

[15] Soares CJ, Raposo LH, Soares PV, Santos-Filho PC, Menezes MS, Soares PB, et al. Effect of different cements on the biomechanical behavior of teeth restored with cast dowel-and-cores-in vitro and FEA analysis. J Prosthodont 2010;19:130-7.

[16] Özcan M, Jonasch M. Effect of cyclic fatigue tests on aging and their translational implications for survival of all-ceramic tooth-borne single crowns and fixed dental prostheses. J Prosthodont 2018;27:364-75.

[17] Yoon HG, Oh HK, Lee D-Y, Shin J-H. 3-D finite element analysis of the effects of post location and loading location on stress distribution in root canals of the mandibular 1st molar. J Appl Oral Sci 2018;26:e20160406.

[18] Aydin AK, Tekkaya AE. Stresses induced by different loadings around weak abutments. J Prosthet Dent 1992;68:879-84.

[19] Lü LW, Meng GW, Liu ZH. Finite element analysis of multi-piece post-crown restoration using different types of adhesives. Int J Oral Sci 2013;5:162-6.

[20] Nicolaisen MH, Bahrami G, Finlay S, Isidor F. Comparison of fatigue resistance and failure modes between metal-ceramic and all-ceramic crowns by cyclic loading in water. J Dent 2014;42:1613-20.

[21] de Kok P, Kleverlaan CJ, de Jager N, Kuijs R, Feilzer AJ. Mechanical performance of implant-supported posterior crowns. J Prosthet Dent 2015;114:59-66.
[22] Villefort RF, Amaral M, Pereira GK, Campos TM, Zhang Y, Bottino MA, et al. Effects of two grading techniques of zirconia material on the fatigue limit of full-contour 3-unit fixed dental prostheses. Dent Mater 2017;33:e155-64.

[23] Tribst JPM, Morais DC, Alonso AA, Dal Piva AMO, Borges ALS. Comparative three-dimensional finite element analysis of implant-supported fixed complete arch mandibular prostheses in two materials. J Indian Prosthodont Soc 2017;17:255-60.

[24] Ausiello P, Ciaramella S, Martorelli M, Lanzotti A, Gloria A, Watts DC. CAD-FE modeling and analysis of class II restorations incorporating resin-composite, glass ionomer and glass ceramic materials. Dent Mater 2017;33:1456-65.

[25] Rigolin FJ, Miranda ME, Flório FM, Basting RT. Evaluation of bond strength between leucite-based and lithium disilicate-based ceramics to dentin after cementation with conventional and self-adhesive resin agents. Acta Odontol Latinoam 2014;27:16-24.

[26] Gozneli R, Kazazoglu E, Ozkan Y. Flexural properties of leucite and lithium disilicate ceramic materials after repeated firings. J Dent Sci 2014;9:144-50.

[27] Bindl A, Richter B, Mörmann WH. Survival of ceramic computer-aided design/manufacturing crowns bonded to preparations with reduced macroretention geometry. Int J Prosthodont 2005;18:219-24.

[28] Hayes A, Duvall N, Wajdowicz M, Roberts H. Effect of endocrown pulp chamber extension depth on molar fracture resistance. Oper Dent 2017;42:327-34.

[29] Biacchi GR, Basting RT. Comparison of fracture strength of endocrowns and glass fiber post-retained conventional crowns. Oper Dent 2012;37:130-6.

[30] Vilchis RJ, Hotta Y, Yamamoto K. Examination of enamel-adhesive interface with focused ion beam and scanning electron microscopy. Am J Orthod Dentofacial Orthop 2007;131:646-50.

[31] Edelhoff D, Ozcan M. To what extent does the longevity of fixed dental prostheses depend on the function of the cement? Working group 4 materials: cementation. Clin Oral Implants Res 2007;18:193-204.

[32] Rohr N, Fischer J. Tooth surface treatment strategies for adhesive cementation. J Adv Prosthodont 2017;9:85-92. 